\title{
El neoliberalismo no es un dogma de fe
}

\author{
Franclsco Javler Iblsate
}

Desde que la teoria de la relatividad ha invadido el campo de la economía se cuestionan las afirmaciones que nos parecian más ciertas. Antes deciamos que dos más dos son cualro, con la sensación de estar en lo cierlo. Pero ahora nos interpelan los economislas preguntando si nos estamos expresando en valores reales o en valores nominales, porque cualro colones de 1992 son iguales a dos colones de 1988, y que no debemos olvidar la dimensión liempo. Este es un sencillo ejemplo de la teoria de la relatividad económica que quien mejor lo entiende es lambién la gente sencilla. Pues si la dimensión tiempo relativiza cosas tan colidianas como el valor de la moneda, que es la medida de valor, algo semejante les tiene que suceder a los modelos económicos sometidos, a la vez, a la dimensión del tiempo y del espacio. En consecuencia, a partir del relalivismo de los modelos económicos deducimos un cuasidogma económico: que los modelos cambian o que los modelos están hechos para remoderlarse. En olras palabras, que no nos podemos aferrar a un modelo concrelo, sino que debemos poner nuestro esluerzo y crealividad en cómo reacomodar el modelo a las exigencias concretas del tiempo y lugar para que el modelo siga manteniendo su valor.

En el pasado siglo y comienzos del presente se consagró el liberalismo; pero aquel liberalismo hizo aguas en los afios de 1930. Como en la recién pasada década también hizo aguas el que decian ser el modelo contrario, resulta que ahora se erige como modelo, a no disculir, el neoliberalismo. Con el mismo derecho, otras escuelas pueden afirmar que estamos iniciando la era del neo-socialismo. Eslas afirmaciones no son juego de palabras, porque un gran cuestionamiento es si el 
neoliberalismo es una corrección o una reencarnación del liberalismo. Algo más fuerte afirma Luis de Sebastián: "El Neoliberalismo una negación del Libealismo". E introduce su pensamiento con estas palabras: "la tesis que defiendo en este articulo es que el fenómeno social o ideológico conocido en nuestro tiempo como neoliberalismo no se parece en nada al liberalismo económico clásico de los aulores de la Economia Polílica Británica de los siglos XVIII y XIX. Antes bien, es un movimiento opuesto a los ideales, molivaciones y objetivos económicos y sociales que luvo aquél. El lérmino neo, afiadido al de liberalismo, resulta de hecho equivalente a no-liberalismo. Esto lo voy a demostrar, mostrando que la ideologia neoliberal de nuestra época es darwinismo social, la doctrina que exalta la necesidad y conveniencia para el conjunto de la sociedad (y de la especie humana) de que algunos miembros de ella, los mejor dolados y capacitados para la compelencia económica, tengan todas las oportunidades de triunfar y sobrevivir en el enirentamienlo de los hombres contra la naturaleza y de los hombres entre si para mantener el control sobre los recursos creadores de riqueza. Por su propia descripción, se hará evidente que el danwinismo social es conceptualmenle contradictorio y práclicamenle incompalible con los valores que promovia o intentaba promover el liberalismo tradicional" (De Sebastián, 1989, pp. 419).

No queda espacio aqui para resumir la lúcida secuencia histórica que, partiendo de la "economia sometida" en el régimen de monarquía absoluta (mercantilismo y monopolio del Estado) se detiene en resallar los ideales de liberlad, igualdad y iIraternidad?; ideales brevemente históricos al igual que el entorno de la "competencia perfecla" en que se desenvolverian, e ideales utópicos, pero soslenidos por las leorias neoclásicas, cuando aparece la "economía sometida por los monopolios y oligopolios". La Teoria de los Sentimientos Morales de A. Smith (...Ninguna sociedad puede ser lloreciente y teliz, si la mayoría de sus miembros son pobres y miserables... (De Sebastián 1989, pp. 425-6), queda silenciada con la gestación que los neoclásicos harán de modelos de equilibrio general de competencia perfecta, y el odioso problema de la distribución se diluye en abstractas lórmulas del contrato de factores de producción. De manera especial, el desarrollo de los "big business" y los grandes empresarios en los EE.UU. llevará a suplantar la Teoria de los Sentimientos Morales por la filosofía del darwinismo social o sobrevivencia del más luerte, predicada por $\mathrm{H}$. Spencer y sus aprovechados discípulos (/bid., pp. 429-30). Con la crisis de 1929, el Estado luvo que intervenir en la economia para impedir una catástrole mayor; cuarenta anos más tarde, con la crisis de los anos setenta resurge la ideología neoliberal: el Estado no es la solución, el Estado es el proble- 
ma. Las "expectativas racionales (de $M$. Freidman/Lucas) anticipan y añulan las acciones del gobierno. Se hace teoría de la imposibilidad de parte del Estado para una acertada gestión macroeconómica. La alternativa es la privalización de aquellas operaciones que pueden ser rentables a empresas privadas. Se consagra la economía del lado de la oferta (supply-side economics), el papel preponderante de los inversores pirivados luera de toda regulación, relegando la economia de la demanda y la mayor inlervención estatal. Los gobiernos conservadores (Reagan, Sra. Talcher...) han logrado lo que era de esperar: "los ricos naluralmente se han hecho más ricos"...

Este imperfecto esquema de los temas tralados en ningún modo suple ni dispensa de la leclura del presente artículo; quien tenga a bien hacer una releclura seguramente eslé de acuerdo con el párrafo final. "Para concluir sólo nos queda ponderar cuán lejos estamos aquí y ahora del ingénuo pensamienlo liberal del siglo $X \mid X, y$ de sus ideales de libertad, igualdad, tralernidad, porque un mundo donde prive el darwinismo social es un mundo en que la libertad no cuenta porque todo está determinado; la igualdad es tolalmente indeseable, porque el avance de la especie humana se basa en la dilerencia de suertes y oportunidades, en la superioridad de algunos sobre los demás; y la fraternidad es una dèbilidad imperdonable, que no puede significar nada real en un mundo competitivo, donde el hombre es para el hombre un lobo feroz" (De Sebastián, p. 435).

Lo que en realidad me ha molivado a recordar este valioso artículo de nuestro profesor y companero, Luis de Sebastián, han sido una cadena de publicaciones lan contrapuestas entre si como suelen ser las posiciones de nuestros diarios matutinos y vespertinos-nocturnos. Con pocos dias de dilerencia, FUSADES dedica su Informe Económico Semanal (17-09-92) a comentar y racionalizar las nuevas medidas económicas del gobierno (IVA a alzas en tarilas de servicios públicos) bajo el lílulo de "Realidad vrs. Populismo Económico", publicación que ciertamente merece ser leida, pensada y criticada en lo que se juzgue convenienle. "La confronlación de ideas y posiciones económicas es muy sana y productiva mientras las reglas del juego sean correctas, y una de ellas es hacer los planteamientos fundamenlados y completos" (Informe № 38). Por su parte, la UNOC en su "Página de Análisis de la Realidad Nacional", (Diario Latino; 27-09-92, p. 8) critica la "manifestación de la realidad desde la visión tecnocrálica en la formulación de la política económica". Da la impresión de que los redactores de esla página popular también preleyeron el artículo arriba mencionado, puesto que refiriéndose a los apologetas o repetidores de la Teoria Del Ajuste Económico del FMI-BM, se expresan de la siguiente manera: "estos sefiores "se- 
rios" creen que en el darwinismo y el determinismo económico, que propugna el prolesor Milton Freidman, han mistificado la visión milhiana del mercado, el que adquiere una categoría inialible como si fuera el dogma de las tres divinas personas... Les vamos a proporcionar un saludable consejo: lean con profundidad la Teoría de los Sentimientos Morales de Adam Smilh. ¿O acaso no se la ensefiaron por ser un texio anatémico como El Capital?"

Estas dos páginas o comunicados (FUSADES y UNOC), escogidos como botón de muestra, expresan no sólo dos posiciones opuestas ante el juego y los efeclos del aclual modelo económico, sino también el distanciamiento que se está abriendo entre los así caliticados enloque tecnócrala y enfoque populista de las medidas económicas. FUSADES justifica y legitima los duros recargos de impueslos en los idus de septiembre (IVA y alza de tarilas de servicios públicos) como medidas necesarias para aliviar el creciente déficit fiscal y para ajustar los precios a los verdaderos costos de producción de las instituciones públicas. De todas maneras, no ha sido idea muy feliz la de ilustrar su pensamiento con la siguiente frase: "el pueblo debe realizar el lan conocido slogan: no hay almuerzo gratis"; porque el pueblo tiene la sensación de que apenas almuerza y de que le suele locar pagar por los que almuerzan mejor.

Tampoco es signo de sana pedagogía social el aplicar un lanlo despectivamente el apodo de "populismo económico" a quienes se oponen al modo e intensidad de aplicación de estas medidas. Es comprensible que se les regrese el boomerang con el calificativo de tecnócratas bien pagados y repelidores de consignas extranjeras. ¿Por qué crear tensiones inúliles? Un aspecto positivo en esle informe de FUSADES es que solicilen de los críticos u oposilores el planteamiento de alternativas discutidas técnicamente y adecuadamente respaldadas. Sin embargo, lo positivo se convierte realmente en algo negativo y en nueva crítica. En primer lugar, anles y dentro del Foro de Concertación Económica y Social, el modelo volado por el FMI y una pequena parte de la población (que entiende de modelos económicos) es un modelo a no disculir, aunque se puedan comentar y paliar algunas injustas conscuencias sociales. En segundo lugar, se han presenlado reformas alternalivas técnicamente discutidas $y$ adecuadamente planteadas, a las cuales ha hecho oidos sordos el poder legislalivo y ejecutivo. A modo de ejemplo sobre el cual mucho se ha escrito, en un país donde la distribución del patrimonio y renta, asi como la estructura tribularia han sido tradicionalmente desiguales y regresivas, se ha procedido a la reducción de los impuestos directos e impuestos a la exportación, cargando consecuentemente el impuesto al valor agregado. En un país donde el déficit fiscal nace, en 
parte, de las grandes inversiones en infraestruclura física que revalúa los patrimonios, y que también nace, en buena parte, de los exagerados e improductivos presupuestos de una guerra aplaudida por unos pocos y danina para las mayorias populares, se alivia relativamente la carga tribularia de los primeros y se transfiere a los segundos. El conocido slogan "no hay almuerzo gratis" no es la mejor publicidad de estas medidas económicas.

Hay suficientes publicaciones de inslitutos de investigación, centros universitarios o políticos para sostener la afirmación de que se están planteando técnica y adecuadamente alternativas económicas. Es triste que muchas de estas propuestas deban esperar los posibles resultados de 1994. Por to que hace a las asociaciones populares, ellas nos plantean sus problemas reales, los problemas de las mayorias. Corresponderá más bien a las instituciones académicas, instituto de investigación o políticos darles una traducción lécnica y justificada, en orden a buscar alternativas sociales; pero lo no adecuado es darle un tratamiento parcialista y despectivo. En un pais donde todo el pueblo es el verdadero pueblo, no podemos exigirle que presente sus demandas en términos lócnicos macroeconómicos o que acepten sumisamente unos ajusles económicos que ahora y antes han sido para ellos simples ajusles económicos. La realidad económica transciende las macrovariables y se percibe como situaciones comprometidas para muchos grupos sociales. Se puede vencer, pero no se puede convencer con lo que ni se entiende ni se acepla.

Si esto no se toma en cuenta, se da pie a reacciones virulentas; he aqui una muestra representaliva. "Nuevamente los aprendices de ideólogos de la política económica actual piensan como los miembros de la Santa Inquisición, que sostenían que todo aquello que iba en contra de lo conocido y aceptado (por ellos) era pecaminoso y por lo tanto objeto del calificativo de herejía. Los inquisidores modernos ya no persiguen..., pero se valen de sofismas que parecen ser reales, ya que se arropan de un instrumental lécnico muy solisticado para arremeter conIra cualquier opositor, senalando la ignorancia de sus razonamientos, utilizando epítetos como "populismo económico" (?) irrealismos, etc.... y que por lo tanlo se niega al pueblo trabajador ignorante el derecho de disentir de las medidas impuestas por los organismos financieros internacionales a través del gobierno ...Eslos sefiores piensan que viven en el país de la Sabiduría y de la Honeslidad, donde la mayoria de los habitanles tienen un título universitario en Economía (Maestro o Doctor), y por ello pueden entender la responsabilidad del gobierno en la adopción de tales o cuales medidas y que además, por vivir en un pais cuyo gobierno administra con transparencia de información, permite a los 
opositores desarrollar capacidad propositiva en materia de alternativas... La población sólo comprende que cada día su salario no le alcanza para sobrevivir y que debe buscar de cualquier forma ingresos para cubrir sus necesidades básicas"... (UNOC, p. 8).

Por supueslo que los problemas y las soluciones alternativas económicas requieren una presentación y representación técnicamente adecuada, y las asociaciones populares o laborales buscan su asesoría y logran hacerlo; pero han venido sintiendo un rechazo o un dar largas al diálogo sincero. Mucho se ha hablado del cumplimiento del calendario de los acuerdos de paz y muchas reprimendas le han llovido al FMLN por este o aquel relraso. Sin embargo, el sector empresarial y quienes le ilustran y apoyan han retrasado por seis meses su coparticipación en el Foro de Concertación utilizando unos argumenlos especiosos y minusválidos Irente al objetivo transcendental que se espera de dicho Foro. Esta sensación de prepotencia y monopolio del saber y de hacer, que desdice de una economía de mercado de libre competencia, viene a reslar competencia y credibilidad a las políticas económicas actuales y a quienes las imponen. Una sensación semejante están experimentando baslantes instituciones de investigación o asociaciones políticas, que lanzan sus críticas y propuestas y se sienten como actores de "lo que el vienlo se llevó", porque algunos volos del Legislativo no han sido técnicamente planteados, pero si han sido generosamente pagados... No todo es tecnicismo ni en la aprobación ni en la exposición y defensa de las nuevas medidas económicas. Si algo vale el argumenlo de autoridad del candidato Bill Clinlon, al criticar el programa de la Agencia de Desarrollo Internacional (AID) aplicado a Honduras y El Salvador, su juicio de valor no deja muy bien parada a esta institución. "Subrayó que la Ley de AID indica que debe asistir a los más pobres de los pobres, pero en el caso de EI Salvador, está asisliendo a los más ricos de los ricos. (Diario Latino, 30/9/92, p. 5). Se trala de una apreciación de un candidato presidencial de los EE.UU., emitida lal vez con ciertos fines propagandisticos; pero coincide con la apreciación de la mayoria de los sectores populares de dentro de El Salvador. Para no herir susceplibilidades y personas concretas no se iranscribe el párrafo anlerior al aquí citado.

Es de esperar que los representanles de las clases laborales presenten técnica y adecuadamente sus demandas y propuestas en el iniciado Foro de Concerlación, que al igual que el Plan de Desarrollo tiene ambas vertientes de económico y social. Mientras tanto las instituciones de invesligación y unidades académicas siguen cumpliendo con su tarea de ser conciencia crítica y constructiva de la realidad nacional. No está fuera de lugar el hacer mención específica de los análisis bastantes avanzados del profesor Aquiles Montoya sobre lo que el califica de "La 
Nueva Economía Popular" (NEP). Esperamos que las siglas no confudan a los leclores: "se trata de una estrategia allernativa y no de un modelo allemalivo" y pretende ser un avance teórico para entender y promover esta nueva realidad de El Salvador (Montoya, 1992b). Veáse también, Montoya 1992a). Todo esluerzo teórico-práclico merece una reflexión, sobre todo si busca el mayor bienestar de las mayorías. Otra línea de acción, aunque el modelo oficial no se pueda disculir o no se vaya a cambiar, es disculir algunos aspectos de su presenlación y de su posible éxito, enmarcado en el entorno de algunas variables de nuestro multiplicador compuesto, que también se preocupa por los posibles catalizadores y frenos de la reactivación económica.

\section{Slete varlables y tres desequillbrlos Igual a dlez}

Es posible hacer una sobresalienle presentación de nuestra situación económica a partir de la integración de siete macrovariables que delerminan tres desequilibrios nacionales. La calíicación de diez se debe a la aparente sencillez junto con la fuerza de convicción con que estos agregados planlean el entramado económico y facilitan las conclusiones o polílicas que deben aplicarse y ya se están aplicando. El pasado mes de abril FUSADES dedica su Boletín Económico-Social al problema de "el exceso de gasto y el desequilibrio externo de la economía salvadoreńa" (FUSADES, 1992). El objetivo es mostrar los laclores que generan nuestra deuda externa, referida especíticamente al déficil en la Cuenta Corriente de la Balanza de Pagos; en resumen, ello se debe a nuestro nivel de gastos por encima de los ingresos. Los recursos provenienles de fuentes externas (remesas familiares, donaciones, repatriación de capital...) generan una apreciación artificial y/o coyuntural del colón, lo cual afecta al desarrollo de las exportaciones. Para restablecer el equilibrio se requiere de un incremento de ahorro público (ingresos-gastos) y del ahorro privado (I-S) que no genere reducción de la inversión, requerida para posibilitar el crecimiento económico. Son estos los objetivos que busca el ajuste estructural y en consecuencia sigue urgiendo su aplicación. A partir de estas premisas se derivan lógicamente un conjunto de medidas económicas adoptadas por el gobiemo, que para unos buscan el equilibrio macroeconómico y que para otros sectores aparecen como una prolongación de la guerra con armamento económico sofisticado; por anadidura, como que la ayuda para ambas guerras descendería de los Estados Unidos.

Puesto que la presentación de estos desequilibrios parte de una concepción y formulación macroeconómica es necesario acoplarse, en forma sencilla, a este ropaje descriptivo. Las variables macroeconómicas describen siluaciones globalmente ciertas, ayudan a compren- 
der las interrelaciones económicas, requiriendo siempre de un análisis eslructural de sus partes componenles a fin de lograr un conocimiento más objetivo de la realidad. Queda pendiente un deber académico: ¿la teoria explica loda o parte de esa realidad?; ¿la leoría toma en cuenla la historia pasada de las variables y de las personas que hacen la variable?...

Con este preámbulo, utilicemos la nomenclatura de la contabilidad nacional. Se parte de un principio razonable: lo que unos gastan otros to ingresan. Por lo tanto, a nivel nacional la fuente de ingresos totales se deriva del gasio o demanda de consumo privado (C), del consumo del gobierno (G), del gasio en inversión (l) y la demanda exlerna de nuestrs exportaciones $(E)$. Adicionando eslos gastos tendriamos la siguiente fórmula de la generación de los ingresos nacionales.

$$
\mathrm{Y}=\mathrm{C}+\mathrm{l}+\mathrm{G}+\mathrm{E}
$$

Siempre a nivel nacional, este conjunto de ingresos se dedican a los siguientes usos o destinos: una parte se dirige a la demanda de bienes de consumo (C); otra parte queda como ahorro voluntario (S); el eslado nos reclama otra parte, a modo de ahorro forzado bajo lorma de impuestos $(T)$, y la producción requiere de la demanda de importaciones (M). Adicionando estos usos o destinos tenemos la siguiente fórmula:

$$
\mathrm{Y}=\mathrm{C}+\mathrm{S}+\mathrm{T}+\mathrm{M}
$$

Puesto que ambas tórmulas nos definen los ingresos totales, en su origen y en su destino, podemos igualar las dos ecuaciones:

$$
\mathrm{C}+\mathrm{I}+\mathrm{G}+\mathrm{E}=\mathrm{Y}=\mathrm{C}+\mathrm{S}+\mathrm{T}+\mathrm{M}
$$

Relacionando por parejas eslas variables $-y$ como el mismo volumen de consumo aparece como ingresos y como destino- derivamos la siguienle formulación macroeconómica:

$$
(I-S)+(G-T)=M-E \text {. }
$$

Si tomamos como valores equivalentes o aproximados el déficil de la balanza comercial (M-E) como representación del délicit de la balanza corriente (excluyendo donaciones), se deduce de esta educación que "el déficil en cuenta corriente es el resultado del exceso del gesto en inversión sobre el ahorro (I-S) y/o del gasto corriente del gobierno sobre 
los ingresos correspondientes (G-T). Esta es una identidad lundamental contable de la balanza de pagos (FUSADES, 1992, p. 3).

Los dalos de la contabilidad nacional para 1990-19991 muestran que el nivel de gaslos (o absorción interna) de la economía salvadorefia fue superior a los ingresos, generando un délicil en cuenta corriente (excluyendo donaciones) por los montos transteridos al siguiente cuadro.

Relación del Exceso de Gasio Privado y Público con el Déficit en Cuenla Corriente. (Millones de colones)

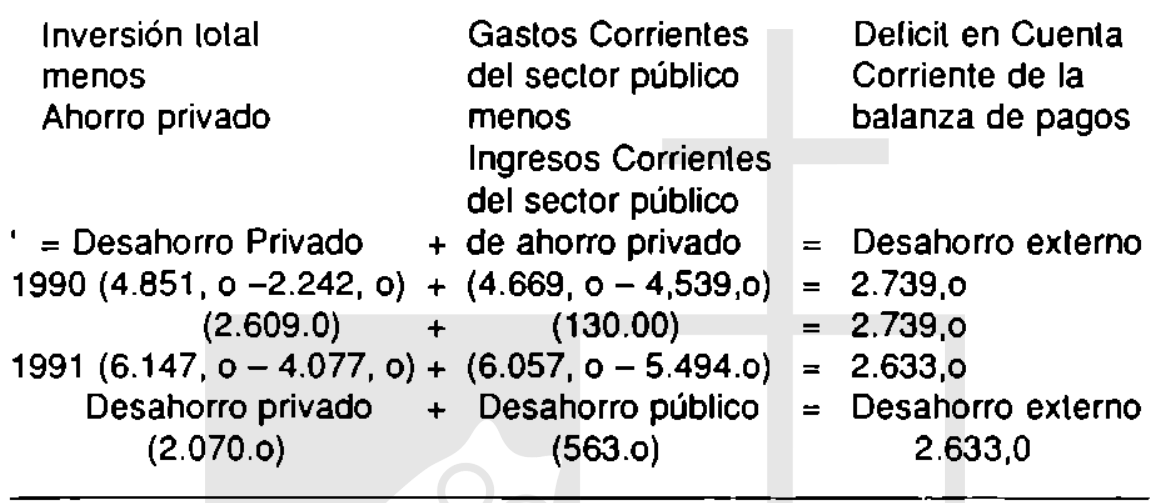

Fuente: BCR (1992), FUSADES (1992, p. 4).

Siguiendo el orden del inlorme, resumimos algunos de sus comentarios. La brecha comercial o déficit en cuenla corriente (excluyendo las donaciones) se redujo en $₫ 160$ millones de 1990 a 1991. Ello se debió al nolorio incremento del ahorro privado que, pese al incremento de la inversión, logra reducir el desahorro privado en $₫ 539$ millones; las medidas monetarias (lasas de inlerés reales...) parecen tener un efeclo positivo. En sentido contrario se movió el desahorro público, que se incremenló en $\$ 433$ millones ya que los gaslos crecieron en mayor proporción que los ingresos. Anade el inlorme de FUSADES: "los principales factores que impiden una mejoría del ahorro público son: a) un coeficiente de tributación por debajo de lo previslo, debido al alto grado de evasión exislente; b) el mayor pago de intereses de la deuda interna consolidada, la cual ha sido reeslructurada a lasas de interés de mercado, y c) los desequilibrios financieros que atrontan las empresas públicas (CEL, ANDA)" (P. 4).

Los cuadros 4 y 5 del informe muestran que el gasto lotal $(C+1+G)$ representan un porcentaje creciente del PIB enlre $1984(107 \%)$ y 1991 $(111,1 \%)$ superando en los tres últimos anos la lasa de inflación. En 
relación al segundo miembro de la igualdad, el déficit en cuenta-corriente (excluyendo donaciones), han influido conjuntamente los bajos precios de los principales productos de exportación, sumado a una apreciación real de la moneda que ascendia a 3,3\% en diciembre de 1991. Por ello "esta sobrevaluación de la moneda ocasionó una pérdida de competitividad de las exporlaciones totales, las cuales crecieron a un lento ritmo de $1,1 \%$ (1991), en contraste con un crecimiento del $17 \%$ obtenido en 1990 en compañia de una depreciación real de la moneda... Las exportaciones no tradicionales al resto del mundo crecieron a una lasa anual del 9,0\% (1991) en contraste con un 33,0\% en 1990" (FUSADES, 1992, p. 5). Igualmente, el informe enfatiza el efeclo de la sobrevaluación de la moneda, que favorece el incremento de las imporlaciones $(11,4 \%$ en 1991, mayor que el $8,7 \%$ en 1990$)$, sumado ello al proceso de desgravación arancelaria. "En resumen, los resultados de las medidas económicas en torno a la corrección del desequilibrio del comercio exterior no fueron satisfactorias; ya que el exceso de gasto interno de la economia, generado en parte por recursos externos (donaciones y remesas familiares) propició una apreciación real de la moneda que lavoreció la importación de bienes y perjudicó el desarrollo y diversilicación de la base exporladora" (FUSADES, 1992, p.b). Como estamos en la fase de presentación de este inlorme, no se af́aden comentarios, de momenlo, a las conclusiones aqui derivadas; el leclor que, por cualquier molivo, quiera afianzar sus conocimientos y posición ante eslas discusiones puede leer provechosamente sobre los programas de ajuste del FMI en Abrego (1991).

A partir de esta ecuación o igualdad lundamental de la balanza de pagos se deduce una primera consecuencia:" El desahorro extemo en la economia salvadorefna durante 1990-1991 fué el resultado de un desahorro privado y público, que se financió tanto de fuentes internas como exlernas".

Se nos advierte acertadamenle que lanto las remesas lamiliares como las donaciones son luentes inestables de ingresos. Sea que se de una repatriación de emigrantes o que las segundas generaciones se instalen en el extranjero, el flujo de divisas por este cauce puede reducirse. También las donaciones pueden ir decreciendo en los próximos anos de acuerdo al buen querer de los donantes, aunque el Programa de Reconstrucción Nacional requiere de un elevado flujo de ayuda externa. En consecuencia, para los redactores del inlorme se impone un esfuerzo real del ajusle interno. Con miras a fundamentar las correspondientes medidas del modelo y restaurar el equilibrio exlemo, "se requiere primeramente de un incremento del ahorro interno en relación con las inversiones; ese mayor excedente de ahorro, sin embargo, no 
Financiamienlo del Geslo Tolal de la Economia: 1990-1991

\begin{tabular}{|c|c|c|}
\hline Fuentes & 1990 & 1991 \\
\hline Rem & 2.447 & 3.49 \\
\hline ㄴ..ㄴ..ㄴ.. & 1.710 & 1.447 \\
\hline de Capilal Oficial y Bancario Nelo & 988 & 386 \\
\hline 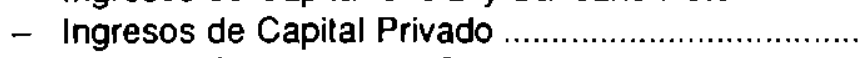 & 2.014 & 997 \\
\hline Corrientes del Sector Público & & \\
\hline (excl & 4.555 & 5.512 \\
\hline iento Interno Neto del Déficit Fiscal. & -395 & 216 \\
\hline - Financimaienlo Propio del Seclor Privado. & 34.321 & 41.167 \\
\hline - Gasto Total Económicos $(\mathrm{C}+\mathrm{l}+\mathrm{G}) \ldots \ldots \ldots \ldots . . .$. & 45.640 & 53.2 \\
\hline
\end{tabular}

Fuente: BCR (1992). Tipo de cambio promedio en 1990 y 1991; $₫ 7.60$ y $₫ 8,04$ por US dólar respeclivamente (FUSADES, 1992, p. 8).

puede oblenerse a expensas de las inversiones necesarias para recuperar el crecimiento" (FUSADES, 1992, p. 9). Las medidas monetarias han lavorecido el crecimiento del ahorro privado, mientras que las medidas fiscales no han logrado reducir los crecientes déficit fiscales.

El informe se cierra con las alternativas de solución que, desde el mes de abril, preanunciaban algunas de las medidas que el gobierno aplicaría en el mes de sepliembre: "los ingresos tributarios no han respondido según lo previsio: por lo lanto. es imporlante irnplementar una reforma fiscal que oriente la eslruclura tribularia hacia impuestos al gasto o consumo (IVA), que reduzca el allo grado de evasión tributaria existente... Para aumentar el ahorro público y elevar la eliciencia global en el uso de los recursos, es necesario revisar las operaciones de las empresas públicas (CEL y ANDA), en particular su política de precios. Una expansión de las exportaciones y reducción del desequilibrio comercial existente, requiere de una mejora en la lasa de cambio real" (FUSADES, 1992, p. 11).

Hasla aqui un breve resumen del informe que, al mismo liempo que cuantifica algunos de nuestros desequilibrios internos y externos. preanuncia - a modo de metereológico económico - las medidas que por su intensidad, simultaneidad y precipitación han generado irritaciones sociales y amagan con descomponer el trole de la inllación programada. Como cualquier análisis macroeconómico es una visión, no superficial, pero sí de la superficie global económica, que puede encubrir componentes o sustratos contrapuestos. Lo que nos da la contabilidad 
nacional es algo cierto, son datos estadisticos, pero pueden y deben variar las interpretaciones sobre el enioque teórico del modelo, sobre la interrelación de las variables y de manera especial sobre la historia, hechos y personas que llevaron a la gestación de esos agregados. Hay que desentrañar la historia de los actores de estas variables, porque lo que realmente existe son los comportamientos de consumidores, de ahorrantes, de inversionistas, de exporladores e imporladores, y hay diversos gaslos e ingresos públicos, asi como hay diversas posiciones y formas de leer la realidad económica. Una vez más la poslura tecnocrática puede entrar en conflicto con los "Sentimientos Morales" de las clases laborales.

A modo de ejemplo y de cuestionamientos siempre pendienles, he aqui unas primeras observaciones. El enfoque general de éste y olros informes arranca de nuestro desequilibrio externo, manifestado en la balanza de pagos, y que hoy por hoy es parcialmente compensado por ayudas y remesas llegadas del exlerior. Del desequilibrio externo, el más preocupante para nuestros acreedores, se pasa a cuantilicar sus causales en los desequilibrios del desahorro o exceso de gasto privado y público. Contablemente, se puede mostrar la explicación. Pero esta explicación, prescindiendo de la posible ignorancia de los modelos y variables macroeconómicas, no convence y no es espontáneamente aceplada para los dos tercios de la población en estado de pobreza. Quienes viven permanentemente en situación de demanda impotente no entienden que a ellos se les pueda clasiticar como gasladores impenilentes. Lo unico que ellos si sienten es que sus ingresos son minimos y que quizá el modelo les quiere castigar por gastar lo que no pueden. $Y$ si lo que el modelo, tal como suena, 10 que pretende es que reduzcan sus gastos no lo encuentran muy moralizanle, es decir no lo ven como un "modelo". No es cuestión de ignorancia macroeconómica, sino de sentimientos morales.

A un esludiante de macroeconomia, que algo ha aprendido de eslas cosas, también le puede llamar la alención que, después de haber dedicado un tiempo lan relevante al estudio y componentes de la función de "consumo", al derivar esla fórmula, llamada fundamental, de la balanza de pagos, la variable consumo (C) se la despeje del radar macroeconómico por la simple razón contable de que el agregado consumo aparece en ambos lados de la igualdad de los ingresos y gasios nacionales. Precisamenle, para las mayorias laborales el gran desequilibrio está dentro y al interior de la función y de la hisloria nacional del consumo. Esta función, en cuanto objetivo y parámetro de valor o eliciencia de cualquier modelo económico, merece ser el punlo de partida de cualquier análisis del bieneslar. Por to tanto, el "encubrimiento" de esta va- 
riable y de sus contradicciones internas deja al descubierto una debilidad del modelo enfocado a la demanda externa. ¿Cómo una economia puede desarrollarse hacia fuera si no demuestra la mayor preocupación por el desarrollo intemo de sus miembros por medio de la variable fundamental del consumo? Por supuesto, el modelo conlabiliza el consumo como un gasto privado, pero sabemos que los promedios macroeconómicos esconden las mayores desigualdades. El hecho de que nuestra propensión marginal a consumir sea muy elevada y cercana a la unidad sabemos que no signilica satisfacciones realizadas, sino más bien impolencia de demanda. Es nomal que los modelos de desarrollo desde dentro complementen esta seria laguna que se resiente en el actual ajuste estructural.

Como el énfasis o la inlención del informe y de su modelo es resallar el desahorro inlerno, se enlazan y comparan, primero, las variables inversión y ahorro (I-S). No puede financiarse la inversión si no hay ahorro; pero lambién es cierto que no suele inducirse la inversión a menos que haya incremento en la demanda de consumo, excepto el caso de inversión forzada por reducción de la demanda que lleva a una reeslructuración tecnológica empresarial. Al sacer del radar macroeconómico la función de consumo, no se toma en cuenla o no se analiza la cadena de repercusiones del efeclo multiplicador $(k=1 / 1-c)$, donde precisamente la variable del consumo (c') es el catalizador del crecimiento interno, y se tiende a sustiluirlo por el catalizador de las exportaciones o posible multiplicador del comercio exterior. Se deja indicado aquí uno de los punlos de divergencia, o por lo menos de cueslionamiento, entre el énlasis por el crecimiento hacia o desde fuera y el desarrollo desde dentro, o si es necesario integrar ambos enfoques de los modelos. Más adelante, utilizaremos una de las formulaciones del multiplicador compuesto que nos ayude a comprender las posibilidades y los obstáculos al desarrollo económico.

Siguiendo el hilo de comentarios al informe aquí esquematizado, no deja de extrafiar a nuestro buen estudiante de macroeconomia y también a las clases laborales que trente al tema de los desahorros internos, privado y público, se apliquen dos explicaciones y dos políticas algo diferentes. Respecto al desahorro privado (I-S), los grupos populares 0 laborales no se sienlen actores ni de hacer inversiones ni de hacer ahorro, pero en el fondo sienlen que el modelo tiende a conlener el consumo, a través de políticas de "salarios reales", favorecer el ahorro y está bien con medidas de inlereses reales, asi como sobre lodo sostener las inversiones empresariales con el conjunto de politicas fiscales. Ya no es cuestión simplemente de variables macroeconómicas sino de grupos sociales que puedan salir perjudicados o tavorecidos. El incre- 
mento de ahorro es algo bueno; el incremenlo de la inversión es necesario, dejando entrever que el exceso de consumo, sin especificar qué consumos, es el que hay que controlar a tin de incrementar el ahorro.

Por lo que hace el desahorro público (G-T), el análisis y las políticas buscan reducir gastos públicos e incrementar los ingresos, en la dirección de las acluales medidas fiscales que frenarian los gaslos sociales del Eslado y trasladarian la carga Iributaria sobre los impuestos indirectos. Con este conjunto de medidas, el consumidor popular se siente agravado por las políticas salariales, por el peso de los impuestos indirectos y por la orientación global del modelo hacia la demanda externa. Vuelve a sentirse marginado dentro del submodelo que algo favorece a los que tienen capacidad de ahorro (inlereses reales) y en mayor medida a inversores y exportadores, máxime si a estos últimos se les ayuda con la devaluación monelaria. Pero conviene ver eslos mismos problemas en visión más dinámica o histórica.

Se dice que uno de nuestros problemas es y ha sido el desahorro privado, pero que ahora, bajo el nuevo gobierno, se inicia una repatriación de capilal privado, acompahando las tradicionales remesas familiares. La conlabilidad nacional abona estos flujos, pero no comenla su historia. Si se repatria capital privado en 1990, quiere decir que anteriormente se habria expatriado, y se darán algunas razones. Eslo significa que si habia ahorro nacional, pero que no se quedaba en el pais. Quienes ahorran y podrian financiar sus inversiones con capital propio, aseguraban su capilal fuera y demandaban ahorro permanente en el país. Entre parénlesis, ha podido ser un buen negocio o un buen seguro sacar dólares a 2,50 y repatriarlos a 8,00 . Por lo tanto hay que distinguir po lo menos dos clases de ahorro. La matriz insumo-produclo-1978 ya deleclaba la relativa capacidad y concentración del ahorro nacional al contabilizar las remuneraciones factoriales de los componentes del valor agregado en las 49 ramas del sector productivo:

Componentes del valor-agregado en las ramas productivas 1978

\begin{tabular}{|c|c|c|}
\hline - Tolal de sueldos y salarios & 2.437 .228 miles- $c$ & $32,38 \%$ \\
\hline - Tolal de Seguridad Social .... & 110.018 & $1,46 \%$ \\
\hline - Total de consumo de capital.. & 301.304 " " " " " & $4,00 \%$ \\
\hline Total de impuestos indirectos netos & 563.313 " " " " " " " " " & $7,47 \%$ \\
\hline Tolal de excedente de explotación.. & 4.026.214 " " " " " " & 53,49 \\
\hline - Tolal del Valor Agregado. & 7.526.077 " " " " " & $=100,00$ \\
\hline
\end{tabular}


Del elevado porcentaje del excedente de explotación pueden deducirse dos cosas: primero la relativa y concentrada capacidad de ahorro existente en el país. Segundo, la elevada fuga de capilal iniciada en el país, que supera con mucho los dalos oficiales y que supone una elevada proporción de nuesıra deuda exlerna. Si se dice que la llegada de remesas y capitales privados (más donaciones) contribuyen a la sobrevaluación del tipo de cambio, también habrá que deducir que la masiva salida de esos capilales privados contribuyó a gestar un mercado paralelo seguido de la devaluación en la década de los 1980, más la consiguiente descapilalización del sistema bancario. Cuando un década más tarde se inicia la privatización del sistema bancario, existe una mora valuada en $\$ 2.300$ millones; nuestros diarios publicaron la lista de las grandes empresas en situación de mora notoria. ¿Quién ha sido el causante del desahorro inlerno: el que gasta un poco más del salario mínimo o el que desahorra fuera?

En dirección contraria aclúan las remesas de emigrantes, llamados popularmente los "pobre-dólares"; aunque vengan de fuera, ésle es un auténtico ahorra nacional. Podrán variar los cálculos de apreciación, que DIES (CENITEC 1992, pp. 5-8) los sitúa en un término medio entre las estadísticas oficiales y las cilras presentadas por el P. Segundo Monles. Lo importante es sefalar que si en la década pasada estas remesas familiares pudieron propiciar el "reciclaje de los pobres-dólares" o fuga de capital, lanlo en la pasada como en la presente década van configurando un porcentaje creciente de las exportaciones de bienes y senvicios (72,5\% en 1991), superando ya el valor de las exporlaciones tradicionales. En otras palabras, son los pobres quienes sensiblemente colaboran al funcionamiento del actual modelo y a financiar con su ahorro, unas inversiones que no siempre son a favor de los más pobres.

No hay lugar para hacer aqui una historia del déticit fiscal, pero si pueden hacerse unas breves reflexiones, sin por ello pretender disculpar errores adminislrativos de pasados gobiemos. En las décadas de los sesenta y selenta el Estado gastó e incrementó su déticil y su deuda externa para linanciar una amplia infraestructura lísica que sirvió a revaluar los patrimonios nacionales que, en buena justicia, deberian haberse Iraducido en mayores impuestos direclos al capilal y a la renta. En la pasada década de los ochenta, sin hablar de la adversa coyuntura inlernacional, el délicit fiscal de los gobiernos se nutrió en gran medida y en forma creciente con los gastos de guerra presupuestados y no presupueslados. Ahora comprendemos mejor que quienes aplaudían la guerra como solución estaban inconscientemente aplaudiendo el correspondiente déficit liscal. Al presentarse a la Asamblea Legislativa el Presu- 
puesto de 1993 casi lodos pensamos que debe reducirse la partida militar sobre lo que presupuestado. Los errores no fueron sólo de los gobiemos que gaslaron, pese a que quienes más apoyaron la guerra se han convertido en los mayores críticos de los gaslos e incompetencia del Eslado. Mirando hacia atrás, quienes más se beneficiaron de las inversiones públicas y quienes más aplaudieron la guerra ¿no son ahora, como grupo global, los que más se benefician con la relativa reducción de los impuestos directos e impueslos a la exportación? Mirando la historia pasada del ahorro-desahorro ¿jugará limpiamente la cadena: reducción de impuestos directos, incremento del ahorro, incremento de la inversión, del empleo y todos los demás ingresos? ¿Es moralmente plausible que, en el interin y mientras juega aquella cadena, los impueslos indireclos, más bien regresivos, sobrelleven un mayor peso de la carga Iribularia? Si lo que se pretende con el IVA (en sí mismo mejor que el timbre) es reducir la evasión fiscal, ¿no se está propiciando otra evasión fiscal mayor con la nueva estructuración regresiva de los impueslos? Estos cuestionamientos son a la vez tecnocrálicos y morales.

Brevemente, por lo que se refiere a dar un nuevo loque depreciativo de la moneda para favorecer las exporlaciones, por lo menos hay que decir que este no es el tiempo más oportuno. Tomando en cuenta la elevada inelasticidad precio-demanda de nuestras importaciones, el efecto más inmediato y más generalizado sería sobre esas alzas de precios, que adicionado a las medidas aplicadas en el mes de septiembre dispararian los precios y la inflación a tasas tales que las mismas exporlaciones lo resentirian y seguirian igualmenle inexportables. No es el momento adecuado para usar este catalizador de bienes exportables, lomado en cuenta las repercusiones que tendría sobre el resto de variables económicas, de manera especial la contracción del consumo real de las mayorías laborales. Bastante premio y consideración ha tenido el gobierno y la Asamblea Legislativa al aprobar la emisión de \$45 millones en bonos para compensar a los catelaleros por la caída abrupta de los precios del café. Nunca se habían emitido esta clase de bonos para relinanciar a los produclores de granos básicos (PROCESO $N^{2} 528$, 1992). Más bien debemos pensar en dos cosas: lo primero es si podemos seguir apoyándonos en esa exporlación tradicional dada la evolución del mercado. Y lo segundo, que con frecuencia el mercado, las leyes de oferta y demanda, nos pegan grandes sustos y entonces clamamos para que el Estado u otros regulen mejor al mercado con convenios más seguros. Lo que aprendemos y hacemos fuera ¿no vale para dentro?

De los suslos y de las crisis se pueden sacar buenas lecciones. Parece que ahora volvemos a reforzar nostalgias y políticas latentes en 
dos direcciones. Frente a un duro, competitivo y competente mercado mundial, comenzamos a revilalizar nueslra vocación Centroamericana. De Eslados Desunidos de Cenlroamérica nos movemos a la constitución de Parlamentos y uniones de libre comercio; y esto hay que aplaudirlo porque nuestro ingreso en el mercado mundial pasa por Centroamérica. Segundo, se ha creado una Comisión de Tecnologia, catalizada por el Ministerio de Economía. Lo importanle es que, ojalá en la orientación de dicha comisión, podamos entrarle a un proceso de reconversión indusIrial, reconversión de la administración pública, reconversión de los gaslos sociales estatales dirigidos a los problemas de educación, salud, nutrición...; porque si no reconvertimos a todos o la mayoría de los hombres las otras reconversaciones quedarán simplemente en reconversión del capital y nada más. Sin ánimo publicitario, se recomienda la lectura del libro editado por (Stein y Anas, 1992) que prolundiza en esta doble línea de la lecnología y del centroamericanismo.

\section{Ayudemos al modelo con otro modelo: el multiplicador com- puesto}

J. Schumpeter dijo: "si Keynes no nos ha hecho keynesianos, nos ha hechos mejores economistas". En los libros de texlo clásicos (los que se ensefian en las clases) dicen los autores que el modelo de Keynes se acepló como solución cuasi-universal hasta la década de los setenta en que apareció una nueva entermedad económica, llamada estanilación: desempleo, contracción e inflación simultáneamenle. Cuando las teorias se debilitan hay que revilalizarlas y se recrean nuevos modelos o se redomelan los anliguos. Asi como han surgido los neoclásicos, los neoliberales, los neosocialistas..., lambién existen los neokeynesianos. Esto significa que bastantes exposiciones e instrumentos de análisis keynesianos siguen teniendo vigencia, y Keynes ocupa un punto relevante en los texlos de macroeconomía. De entre estas partes válidas entresacamos el principio del multiplicador que él popularizó en su Teoría General del Empleo..., para sacer a sus economias de la siluación de desempleo y contracción generalizada. También nosotros estamos enfrentados con el mismo problema del gran desempleo y de la reactivación económica. Como no hay recetas universales para cada tiempo y cada lugar nos debemos preguntar cuáles pueden ser los motores calalizadores de nuestra recuperación económica y cuáles pueden ser los molores catalizadores de nuestra recuperación económica y cuáles son de hecho los frenos o fallas estructurales, que dificultan el repunte de nuestro desarrollo.

Por lo tanto, lo que aquí se va a proponer no es una alternaliva de modelo económico, sino una ayuda para reorientar y quizás corregir lo 
que actualmente estamos haciendo. La razón es que siendo el principio del multiplicador un engranaje económico que llevaría a un incremento de la renta-producción-empleo-ingresos-consumo-inversión..., surge la pregunla ¿por qué nuestro multiplicador no funciona adecuadamente? Al tratar de responder a esta pregunta sin duda descubrimos una serie de averias o fallas estructurales de nuestro mercado, que es preciso enmendar para que luncione cualquier clase de modelo económico. Para ello, ulilizando una de las lormulaciones del multiplicador compuesto, ubicamos en el numerador alguno de los catalizadores o variables molores de la recuperación; en el denominador se alistan un conjunio de fugas o lallas estructurales que frenan la expansión. Esto lo expresamos en la siguiente lormulación.

$$
\Delta Y=C+l+G+(E-M) / s^{\prime}+m^{\prime}+l^{\prime}+d^{\prime}+e^{\prime}+\ldots
$$

En el numerador volvemos a reconocer las variables que integran la lormación de nuestro producto-ingreso nacional. La prelendida novedad es que pueden formarse otras parejas e interdependencias de las variables del numerador y del denominador, cuyas siglas significan los siguientes valores:

- s' es la propensión a ahorrar y su deslino;

- m' es la propensión a importar y su composición;

- l' es la estruclura tributaria en su proceso hislórico;

- d' es la estructura del endeudamiento nacional;

- e' es la propensión a especular;

- y los puntos suspensivos signilican otras variables socio-políticas.

Por supuesto que no se trata aqui de exponer un cićlo de macroeconomia, sino tratar brevemenle de conocer un poco mejor nuestra realidad. La primera aparente novedad es que la variable "Consumo" (C) no la despejamos luera del radar económico, porque el consumo (C), además de ser el principal objetivo ético de cualquier modelo, es por si mismo el principal catalizador del crecimiento. La demanda interna es la pieza principal de cualquier economia de empresa, a no ser que se prefiera imponer un seudo modelo de "economia de mercado externo". La pregunta clave es ¿por qué en nuestra economia el consumo interno juega poco como catalizador?. Para responder a esta pregunta hay que entrelazar el consumo (C) con la propensión a ahorrar ( $\mathrm{s}^{\prime}$ ), las dos dependientes, no del nivel de renta, sino de la eslructura de dislribución de la renta. Esto nos lleva a trasladar en porcenlajes nuestra Curva de Lorenz hislórica; para evilar pendencias inútiles entre gobiernos de hoy y ayer, tomando el agua desde más arriba (Cuadro 1). 
Estruclura de la distribución del ingreso: 1961-1979. El Salvador

- Años $20 \%$ más pobres $30 \%$ bajo la $30 \%$ sobre la $20 \%$ más allo mediana mediana

\begin{tabular}{lllll}
\hline-1961 & $5,5 \%$ & $10,5 \%$ & $22,6 \%$ & $61,4 \%$ \\
-1969 & $3,7 \%$ & $14,9 \%$ & $30,6 \%$ & $50,8 \%$ \\
-1979 & $2,0 \%$ & $10,0 \%$ & $22,0 \%$ & $66,0 \%$ \\
\hline
\end{tabular}

Fuenle: DIES-CENITEC: (1991, p. 14).

Para el trienio 1988-1990 disponemos de las estadísticas de distribución del ingreso familiar mensual de los hogares "urbanos" por deciles, reportados por GAES/MIPLAN (Cuadro 2). Los números del cuadro interior son procentajes del ingreso tolal urbano distribuido entre la población por deciles de menores a mayores ingresos.

Cuadro 2

Dislribución del ingreso familiar urbano-por deciles: 1988-1990

\begin{tabular}{lcccccccccc}
\hline Años & $1^{9}$ & $2^{2}$ & $3^{2}$ & $4^{0}$ & $5^{9}$ & $6^{0}$ & $7^{0}$ & $8^{9}$ & $9^{9}$ & $1^{9}$ \\
\hline $1988-1,81$ & $--3,74--5,5--6,24--7,45--9,04-10,74--12,52-15,50-27,48$ \\
$1989-1,51--3,08--4,2--5,33--6,51--7,92--$ & $9,87--12,35-16,79-32,34$ \\
$1990-1,21--2,73--4,0--5,25--6,45--7,79--$ & $9,76--12,48-$ & $-7,01-33,28$ \\
\hline
\end{tabular}

Fuente. GAES-MIPLAN (199p, p. 114).

Para las décadas anteriores puede leerse provechosamente el artículo sobre la concentración económica en El Salvador (Sevilla, 1984) que a su vez recoge los resultados de una serie de investigaciones. Para la situación presente en el sector urbano, el cuadro superior nos dice bastante sobre el tema de la concentración de los ingresos y la extensión de la pobreza en el seclor urbano. En relación al sector rural, sin muchas estadísticas y sin tiligranas ideológicas, to que en forma principal está Irenendo los acuerdos de paz es el radical problema de la distribución de lierras. Los mismos proyectos del Plan de Reconstrucción y de las remodelaciones del FISS nos llevan a pensar que más de una reconstrucción hay que partir de una construcción desde cero.

Quienes están más preocupados por nuestra deteriorada fachada y deuda externa no sienten ni resienten la profundización de la pobreza y la demanda impotente que manifiestan estos cuadros y deciles. Recor- 
demos que la pobreza es la mayor violencia y suele venir acompañada de otras clases de violencia: comisión de la verdad. Resulta un lanto irónico poner la solución simplemente en una economia de mercado competilivo; ¿competitilivo entre quiénes? Si el problema de la extrema pobreza es tan primordial como indican los discursos oliciales, cabe preguntarse si es posible ir solventando el problema de la pobreza a partir de los mismos pobres. Para responder a este interrogante se hizo un ejercicio práctico y mental en 1987, una vez que disponiamos de nuestras matrices insumo-producto para poder dar un tratamienlo econométrico a este trabajo. El actual Plan de Reconslrucción pudiera servir de escenario de lo que este ejercicio queria demostrar.

Se parte del supuesto siguiente: el Estado realiza un proyecto o gasto de inversión inicial por valor de $₫ 100$ millones, generando ingresos equivalente en sectores desempleados de la población. Eslos ingresos se dedicarán a satisfacer las demandas lipicas de la canasla Iamiliar, solicilando de los correspondientes sectores la oferla de esos bienes. A partir de este gasto inicial y en orden a satisfacer esta demanda se fueron calculando, a lo largo de seis ańos, utilizando el juego del multiplicador y nuesıras matrices intersectoriales, cuáles serían los efeclos sobre el incremento de la producción lotal, en las horas de empleo requeridas, en los ingresos de los trabajadores y de los empresarios y en la demanda de imporlaciones. El resullado de este ejercicio práctico y mental se refleja en el cuadro 3.

Cuadro 3

Periodo Producción Empleo:D/H Ingresos Ingresos Imporlaciones trabajo empresa

\begin{tabular}{rrr|rrr}
\hline-1 & $134,006.529$ & 2.866 .419 & $15,026.750$ & $60,869.599$ & $15,705.973$ \\
-2 & $76,454.241$ & $1,501.687$ & $7,894.711$ & $26,948.539$ & $12,184.736$ \\
-3 & $35,099.372$ & 689.409 & $3,624.382$ & $12,371.803$ & $5,593.890$ \\
-4 & $16,133.768$ & 316.501 & $1,663.917$ & $5,679.770$ & $2,568.098$ \\
-5 & $7,397.669$ & 148.302 & 763.888 & $2,607.525$ & $1,178.988$ \\
-6 & $3,396.195$ & 66.707 & 350.693 & $1,197.089$ & 541.262 \\
\hline
\end{tabular}

$=$ Totales $272,467.774 \quad 5,586.026 \quad 29,324.341 \quad 109,674.325 \quad 37,772.947$

Nota: los valores están expresados en $₫$, excepto el empleo en dias/hombre.

El desarrollo de esla investigación se resume bajo el título de "Necesidades básicas y reactivación de la economia". habiéndose hecho aplicaciones posteriores a nuestra actual situación (Instituto de Investigacio- 
nes Económicas, 1987; Ibisate 1992a). El aporte práctico de esta invesligación es que nos muestra que los seclores que responderian a la demanda y satisfacción de las necesidades básicas lienen una elevada capacidad para la reactivación económica, por ser seclores claves relativamente como demandantes y oferentes de insumos intersecloriales. La investigación es un ejercicio práctico en este doble sentido: en la demanda posible de los más pobres hay una elevada capacidad de reactivación económica, al ser estas ramas dinamizantes de la economia; esta capacidad puede forlalecerse o reducirse de acuerdo a las politicas fiscales: las actuales políticas han oplado por la segunda alternativa. Por lo cual se hace una distinción entre "economía social de mercado y economia social con mercado" (Ibisale, 1989).

Este ejercicio, calificado de práctico y mental, nos lleva a contraponer las variables consumo (C) y propensión a ahorrar ( $\left.s^{\prime}\right)$. No se analiza aqui el ahorro (S) como la variable positiva que sirve a financiar la inversión, sino la propensión a ahorrar que financia el desarrollo del multiplicador en sectores productivos extranjeros. Desde el punto de visla del efeclo mulliplicador y de la reactivación económica que ahora nos preocupa, resulta que la propensión a ahorrar (s') liene tanla fuerza para frenar el desarrollo de nuestro mercado como el consumo nacional para impulsarlo. En virtud de la elevada disparidad de los ingresos (cuadros de la curva de Lorenz) buena parte de las rentas internas derivan hacia el exlerior bajo forma de salida o luga de capilal; el multiplicador no juega. También existe otra tuga cuando parte de los ingresos se dedican a demanda interna de importaciones de bienes de consumo relativamente sunluarios - Iruto del efecto-imilación- en las ramas de alimentación, vestuario, enseres domésticos, educación-salud, distracciones elc., alenladas por la publicidad y marcas extranjeras. No se trala de suprimir las importaciones convenientes, ni de soslener producción nacional de mala calidad, sino de cuestionar aquellas importaciones suntuarias que no encajan en una economia de posiguerra y de pobreza generalizada. Es una cueslión de fina élica publicilaria y de sumisión a los intereses de algunas multinacionales que desbancan la producción nacional. Por supueslo, tampoco se Irata aqui de Irenar las importaciones de equipo y similares, necesarias a nuestro proceso de producción. Por to tanto el ahorro (s') aqui analizado no es renta menos consumo, sino ahorro contra consumo. Esla contraposición es la que caracteriza a nuestra economía de mercado, que podrá ser competitiva, pero no es competente si no responde a las mayores necesidades generales.

En anteriores comentarios sobre la construcción de posiguerra, teniendo en mente el proceso de la reconsirucción europea, recordábamos que no hay posible reconstrucción sin colaboración de todos y sin 
un sacrilicio generalizado. La reconstrucción exige sacrificar por un tiempo las "zonas rosas económicas, para asenlarnos en una economía de mayor sobriedad y austeridad. Si nuestro mercado produclivo y el sistema monetario no comulga con estas recomendaciones, por motivos de rentabilidad monelaria de corto plazo, este mercado y las polílicas que lo acompañan difícilmente resolverá el problema de la extrema pobreza. Prescindiendo de lo que pueda suceder en 1994, la "nueva economia popular" (Monloya 1992b), deberá desarrollarse por cuenta propia y al margen del modelo oficial.

Relacionamos ahora otro catalizador como es el Gasto Público (G) con la estruclura tributaria (l'), por cuanto son los impueslos una de sus principales fuenles de financiamiento. Supueslos los comentarios antes adelantados, sólo queda por decir que nuestra estruclura Iribularia ha sido tradicionalmente regresiva. En un pais, donde las persislenles curvas de Lorenz muestran la desigual distribución del palrimonio y rentas, sería de esperar que los impuestos directos aporlaran un elevado porcentaje de la carga liscal por razones de equidad y justicia redislribuliva. Pero las series del mediano-largo plazo nos muestran que los ingresos tributarios crecen en menor proporción que el produclo nacional. Que pese a las cuantiosas inversiones públicas, que revalúan los patrimonios-rentas asi beneficiados, con todo los ingresos tributarios se han nutrido, en promedio, de un lercio de impuestos directos y dos tercios de indireclos. Por ser éste problema antiguo, el Plan de Desearrollo Económico y Social 1973-1977 dedica algunos acápiles a la "percepción de ingresos". En estas páginas ya se hace mención a la introducción del IVA. "En cuanlo a los impueslos indirectos se hace necesaria su modernización, principalmente el de limbre para convertirlo a un impuesto sobre el consumo interno o valor agregado, con delerminados criterios de seleclividad en cuanto a la clase de consumo y como complemenlo a la política arancelaria" (CONAPLAN, pp. 93).

A diferencia de la actual publicidad, que simplemente compara el IVA con el limbre para que gane el más moderno -y se recorte la evasión fiscal-, el Plan de Desarrollo habla primero, en esa misma página de la evasión fiscal Irente a los impuestos directos. "En realidad, la escala del. impuesto sobre la renta es la más alta de Centroamérica y tal como se ha expuesto anleriormenle, lo que hace fatta es el establecimiento de un sistema efectivo de cobro. En el impueslo sobre el capilal es notoria la subvaluación de los bienes raices para efectos de la declaración, lo que a su vez refleja las deficiencias administralivas. En esle campo debe impulsarse la aplicación del catrato tiscal, que permitirá una adecuada clasificación y valuación de la propiedad inmobiliaria. Asimismo, las obras de inlraeslructura ejecutadas por el Estado, particularmente 
carrerteras, han elevado considerablemenle el valor de los bienes adyacentes, sin que tal situación se manilieste en los ingresos fiscales. Esta situación, además de promover una verdadera especulación, no permite que el Estado recupere el costo de sus inversiones. Por lo general, esos bienes raices pertenecen a personas de altos ingresos. En este campo se recomienda la creación de un impuesto sobre la plusvalia de bienes raices" (lbid.)

Las dificultades técnicas del sistema administrativo junto con la evasión fiscal de los sectores de altos ingresos siguen manteniendo la misma estructura tributaria regresiva, que tiende aclualmenle a reforzarse con la propuesta de supresión del impuesto al patrimonio, la reducción del impuesto a las rentas, por motivos de simplificación, la desgravación de los impueslos indireclos a las exportaciones, con el mayor énfasis en los impuestos indirectos (IVA...). El resullado es que la carga tributaria en El Salvador, comparada con olros paises lalinoamericanos, sigue siendo baja y regresiva. Por la actualidad e importancia del lema se citan algunos de los análisis recientemente publicados (Abrego, 1992; IIES, 1992; McGuire, 1990).

Otra variable motriz y fundamental para nuestro desarrollo es la inversión (I). No hace falta alargarse a comentar lo que es obvio y sólo vale la pena delenerse un momento en lo que puede ser más contencioso. En nuestra fórmula del multiplicador compuesto, relacionamos la inversión privada y pública con la propensión a ahorrar (s') del denominador, concentrándose ahora en el ahorro adminislrado por el sistema bancario privatizado. Una primera advertencia es que el sistema bancario se ha privalizado, pero el ahorro sigue siendo público, por cuanto es un ahorro del público y para bien del público. Por esia razón, dicen, se privatizó la banca, para hacerla más democrálica, una especie de "capitalismo popular". Una segunda advertencia, sacada de nuestro Plan de Desarrollo Económico y Social, 1989-1994, es que al Estado se le encomiendan programas sociales de primordial importancia como son los sectores de educación, salud-nutrición, vivienda, lamilia, previsión social, sector laboral y política ecológica (MIPLAN, 1990, pp. 63ss), además de olras infraestructuras físicas alli mencionadas (pp. $60 \mathrm{ss}$ ). Tenemos ahi un amplio listado de inversiones sociales ylfísiças, lodas ellas requeridas para el desarrollo económico.

Ante esta siluación de grandes inversiones frente a un ahorro relativamente escaso, es probable que se llegue a una solución salomónica. El sistema bancario privalizado se encargará de alender el 'inanciamiento del seclor poductivo privado; las posibles y esperadas ayudas y ahorro exlerno financiarán las inversiones públicas, hasta donde alcance 
y dado el papel subsidiario del Estado. Esta probable solución, regida por la rentabilidad monetaria de corto plazo, desnaturaliza el carácler del ahorro bancario, que sigue siendo público y de un público que también se beneficia de las inversiones sociales del Estado. Además, en lorma direcla o indirecla, los depósitos bancarios se nutren también de las remesas lamiliares, que si tienen en su origen a los pobres lambién en su destino los debieran tener presentes. Si se impone esa solución salomónica no queda muy claro el carácter democrálico o capilalismopopular del sistema bancario, a no ser que el título se refiera sólo a la apropiación de algunas acciones por los empleados de eslas instituciones; pero eso no basta para hacer una banca democrática. tampoco sugerimos, en el otro extremo, que se emita crédito inorgánico para cualquier gası de la administración pública, algo distinlo de la inversión social.

De nuevo conviene hacer uso o apoyarse en un ejercicio práctico y mental si buscamos un equilibrado desarrollo económico y social. Resulla que los sectores llamados sociales (educación, salud-nulrición-vivienda... ecología) son los más económico que existe, precisamente porque son sociales, porque son sectores dinamizantes y prerrequisilos indispensables de cualquier desarrollo económico. Sin desarrollo de las personas no hay desarrollo. En realidad, esto es tan claro y tan universalmente reconocido que, precisamente por eso decimos que si pero hacemos que no. Este es el reto de nuestro sistema bancario; algo de orienlación y de ayuda le puede venir de nuestras matrices intersecloriales que, al sehalar cuáles son los sectores más dinamizantes del desarrollo de las personas y de los bienes, han sido utilizadas en otros paises para orientar el crédito a aquellas inversiones que más impactan el juego del efecto multiplicador. La privatización debe ser social para no convertirse en desprivatización (Ibisale, 1990b).

Variables pivoles del actual modelo y catalizadores del multiplicador en economías abiertas son las exportaciones-importaciones, de acuerdo a los signos de la balanza comercial. Sobre lo ya comentado anteriormenle, unos puntos de addenda. Se nos presenta una reciente novedad: el auge inicial de las exportaciones no tradicionales. Ya vimos en el informe de FUSADES que debido a la actual sobrevaluación del colón "las exportaciones no tradicionales al resto del mundo crecieron a una tasa anual de $9,0 \%$ en 1991, en conlraste con un 33,0\% en 1990". Parte de la explicación puede hallarse en esa causal que, por sí sola no justifica una desaceleración tan elevada. Tomando en cuenta que dichas exportaciones no tradicionales se han incrementado dentro y fuera del área centroamericana, parte de la explicación puede tener otras razones: en primer lugar, se trata de exportaciones no tradicionales, y por 
ello no se ha adquirido todavia la suficiente pericia en el proceso de comercialización. Puede deberse a proteccionismos, condiciones de calidad, cuotas permitidas, etc. Hay también otros aspeclos que conviene reflexionar.

Al analizar, en anterior publicación, las calegorias de las exportacio- $\mathrm{J}$ nes no-tradicionales a Centroamérica, como primer puente hacia el mercado mundial, se hacia el siguiente comentario. "Los cuadros 2 y 3 muestran que las mismas exportaciones no-tradicionales tienen como destino paises de dentro y fuera del istmo centroamericano, aunque no en la misma proporción ...Se diría que podemos penetrar el mercado internacional con produclos del reino vegetal, textiles, además de calzado, si no hubiera restricciones a estos artículos. Eslo significa que los avances tecnológicos aplicados a estos productos y el aprendizaje del mercado ayudarán a penetrar cuantitaliva y cualitativamente en el mercado internacional. Los avances tecnológicos, traducidos en mejor calidad y menores coslos de producción unilarios expandirían lanto el mercado interno y externo de las empresas. Por ello lodas las medidas que se tomen en pro de una mejor equidistribución de los ingresos o con vistas a la generación de empleos servirian a reactivar el mercado y la capacidad instalada de las empresas. Adicionalmenle, un estadio superior a recorrer por las exporlaciones no-tradicionales es ir sustituyendo productos exportados en su tase primiliva por produclos internamente manufaclurados por la agroindustria. Se trata de las cadenas productivas río-abajo, que se comentan más adelante" Ibisate, 1992b).

El entorno económico en que se redactan eslas líneas loma en cuenla, por una parte, la dificil coyunlura de nuestras exporlaciones Iradicionales en el mercado mundial, y por otro lado los requerimientos de una renovación tecnológica en la transformación interna de las exportaciones no-Iradicionales y en un contexto de renovada reinlegración centroamericana. En Slein y Arias (1992), se punlualiza desde la inlroducción ește enioque: "el elemento bisagra que vincula y potencia las relaciones recursos-produclividad, gente-naluraleza, sociedad-Eslado, mercado inlerno-mercado externo, trabajo, industrialización, formación profesional, tecnología, inversión, intraestructura, comercio, energia y medio ambiente, eslá en la articulación agricultura-industria, que es la tesis que en esle volumen se explora...". (cilado en lbisate, 1992b, p. 351). Esta estrategia se entiende aplicada a nivel regional-centroamericano, como puente hacia el reslo del mercado mundial. Esta seria una de las áreas en que esperamos trabaje la Comisión de Tecnologia juramenlada por el Presidente de la República.

En este enfoque, la renovación lecnológica o reconversión industrial 


\section{Cuadro 4}

El Salvador: exportaclones e Importaciones por paises enero-diclembre de 1991 (mlles de \$-USA)

\begin{tabular}{|c|c|c|c|c|c|c|}
\hline \multirow[b]{2}{*}{ Pals o región } & \multicolumn{2}{|c|}{ EXPORTACIONES } & \multicolumn{2}{|c|}{ IMPORTACIONES } & \multicolumn{2}{|c|}{ SALDOS } \\
\hline & VALOA & $\%$ & VALOR & $\%$ & VALOR & $\%$ \\
\hline TOTAL & 573.222 & 100.0 & 1.415 .443 & 100.0 & 842.221 & 100.0 \\
\hline I. Países Industriales & 336.827 & 58.8 & 802.686 & 56.7 & 465.859 & 55.3 \\
\hline A. Grupo de los slele & 323.687 & 56.5 & 758.285 & 53.6 & 434.598 & 51.6 \\
\hline Estados Unidos & 191.072 & 33.3 & 574.391 & 40.6 & 383.319 & 45.5 \\
\hline -Alemania & 105.422 & 18.4 & 59.911 & 4.2 & 45.511 & 5.4 \\
\hline -Japón & 15.597 & 2.7 & 68.268 & 4.8 & 52.671 & 6.3 \\
\hline -Francia & 1.763 & 0.3 & 13.412 & 0.9 & 11.649 & 1.4 \\
\hline - Peino Unido & 1.577 & 0.3 & 20.595 & 1.5 & 19.018 & 2.3 \\
\hline —Canadá & 5.241 & 0.9 & 13.301 & 0.9 & 8.060 & 1.0 \\
\hline -Ilalia & 3.015 & 0.5 & 8.407 & 0.6 & 5.392 & 0.6 \\
\hline B. Otros & 13.140 & 2.3 & 44.401 & 3.1 & 31.261 & 3.7 \\
\hline 一España & 2.661 & 0.5 & 0.720 & 0.8 & 8.059 & 1.0 \\
\hline -Bélgica-Lux & 4.137 & 0.7 & 11.998 & 0.8 & 7.861 & 0.9 \\
\hline -Holanda & 5.289 & 0.9 & 18.529 & 1.3 & 13.240 & 1.6 \\
\hline -Dinamarca & 1.053 & 0.2 & 3.154 & 0.2 & 2.101 & 0.2 \\
\hline II. Palses en Desarrollo & 17.853 & 38.0 & 542.324 & 38.3 & 324.471 & 38.5 \\
\hline A. Centroamérica & 193.732 & 33.8 & 241.490 & 17.1 & 47.758 & 5.7 \\
\hline -Guatemala & 107.600 & 18.8 & 163.893 & 11.6 & 56.293 & 6.7 \\
\hline - Costa Rica & 43.927 & 7.7 & 41.428 & 2.9 & 2.499 & 0.3 \\
\hline -Nicaragua & 20.682 & 3.6 & 18.661 & 1.3 & 2.021 & 0.2 \\
\hline -Honduras & 21.523 & 3.8 & 17.508 & 1.2 & 4.015 & 0.5 \\
\hline B. OTROS & 24.121 & 4.2 & 300.834 & 21.3 & 276.713 & 32.9 \\
\hline $\begin{array}{l}\text {-Panamá } \\
\text { (y Zona Canal) }\end{array}$ & 9.937 & 1.7 & 45.412 & 3.2 & 35.475 & 4.2 \\
\hline -Argentina & 1.196 & 0.2 & 10.113 & 0.7 & 8.917 & 1.1 \\
\hline -Brasil & 0 & 0.0 & 29.036 & 2.1 & 29.036 & 3.4 \\
\hline -Chile & 555 & 0.1 & 6.265 & 0.4 & 5.710 & 0.7 \\
\hline -México & 8.109 & 1.4 & 137.065 & 9.7 & 128.956 & 15.3 \\
\hline -Venezuela & 184 & 0.0 & 57.641 & 4.1 & 57.457 & 6.8 \\
\hline -Belice & 4.138 & 0.7 & 36 & 0.0 & 4.102 & 0.5 \\
\hline -Taiwan & 2 & 0.0 & 15.266 & 1.1 & 15.264 & 1.8 \\
\hline III. Demás paises & 18.542 & 3.2 & 70.433 & 5.0 & 51.891 & 6.2 \\
\hline
\end{tabular}

Fuente: BCR. Sección de Balanza de Pagos. Marzo de 1992. 
desciende al campo de las exportaciones no-Iradicionales, ensamblando el desarrollo hacia fuera con el desarrollo hacia dentro, donde tanto el "desde dentro" como el primer "hacia fuera" es el isimo centroamericano. La renovación tecnológica se espera que beneficie tanto a nuestras exporlaciones como a nuestras importaciones. Como indicador significativo se traslada el cuadro adjunto que muestra nuestro déficit comercial con lodos los bloques (no paises individuales) con los que nos relacionamos comercialmente (Cuadro 4).

Esle esluerzo por diversificar, tecnificando, nuestras exportaciones se hace tanto más urgenle dada la necesidad y tendencia creciente de nuestras imporlaciones, que de 1987 a 1991 se incrementan en un $226 \%$ a precios corrientes. En orden de magnitud los bienes inlermedios representan el $50,5 \%$ de las importaciones en 1991, seguido de los bienes de consumo y de capital, que se distribuyen el otro $50 \%$. En orden de tasa de crecimiento, los bienes de consumo duraderos y no duraderos muestran un alza mayor $(247 \%)$, seguidos de los bienes intermedios (226\%) y de los bienes de capital (205\%). La mayor liberalización del comercio, la reducción arancelaria y la relaliva sobrevaluación de la moneda explican esios incrementos que han hecho posible la reaclivación global de la economía. Sin embargo, hablando de reaclivación económica y de recuperación de postguerra, no todas las importaciones son igualmenle reactivadoras de la economía, e incluso algunas importaciones se salen tolalmenle de esla calegoria. Una vez más, las matrices intersectoriales son una buena escuela de apendizaje de imporlaciones primordiales y secundarias o inútiles. Uniendo las esladisticas de la distribución de la renla nacional con lo que observamos a simple vista en nuestras calles y comercio más de lujo, amén de la publicidad, un buen porcentaje de importaciones de bienes de consumo duradero y no duraderos ni sirven a la reactivación económica ni encajan en un entorno de pobreza y de aflicliva deuda exlerna. El "efecloimilación" alentado por la publicidad campea, a partir de las importaciones sunluarias que informan y delorman parte del mercado nacional. Este es un caso de ahorro ni virtuoso, ni reactivanle de la economía.

En el denominador de nuestra fórmula aparece como un freno y obstáculo del efecto multiplicador la siluación estruclural de nuestra deuda (d'). No vamos a hablar aqui de la impagable deuda exlerna, cuyo servicio puede absorber hasta el $40-50 \%$ del valor de nuestras exportaciones; éste es un efecto estructural de una situación estructural en proceso de retroalimentación. Tampoco nos detenemos en el doble desahorro inlerno, privado-público, que deriva en el desahorro exlerno descrito en el informe de FUSADES. Siendo eslo tan importanle, con todo los análi- 
sis macroeconómicos corren el peligro de tocar langencialmente o de pasar por alto la deuda estruclural de las mayorias laborales, una deuda que siempre crece y pocos ayudan a pagarla. Es tan hiriente la siluación que, al igual que en la parábola del buen samaritano, prelerimos pasar de largo e ir al templo y pedir a Dios que arregle el problema; y que los curas no se metan en estos "bonches". Los mismos datos de inllación, desempleo, distribución de la renla son aflictivos. Cuando se inicia la inflación en nueslro pais los precios duplican de 1972 a 1978. Cuando se traslada la escala al afio base $1978=100$, nos encontramos que a julio de 1992 el IPC ha pasado al índice 935,29 y los alimentos se siluaan a nivel del indice 1.208,94. ¿Cómo puede aliviarse o servirse esla deuda interna y externa, cuando la descomposición de los salarios reales se reducen a inira-mínimos, de acuerdo a los serios esludios que CENITEC, $C$. Briones y olros han realizado sobre la siluación de pobreza en El Salvador? Por af́adidura, la guerra, que nació de esia eslructura de pobreza, profundizó aún más la deuda permanenle. Adicionalmente, las teorías y modelos en boga no preferencian de hecho los gases sociales del Estado, ¿ente subsidiario?, y con las políticas fiscales las agravan, de acuerdo al senlir y resenlir popular. Sin alargarnos más, volvemos al punlo de partida: "ninguna sociedad puede ser floreciente y teliz, si la mayoria de sus miembros son pobres y miserables" (A. Smilh). Talvez esı́o suene a "populismo económico". Se está haciendo un mito de la lecha-cumbre 31 de octubre; la guerra fue cruel, pero en palabras de Ghandi, la pobreza es la mayor violencia.

Por lo menos este breve recorrido sobre la iormulación del mulliplicador compuesto nos ha iniciado simplemente en algunas fallas eslruclurales que trenan la expansión y el desarrollo. No es esto un nuevo modelo econórnico, pero quizás sirve a decir por dónde no hay que ir.

Para lerminar, dos palabras sobre la variable especulación (e'), pero no aplicada a los títulos valores del análisis keynesiano, ni a los títulos dólares (fuga de capilal) que han debilitado nuestra economía. Especular, etimológicamenle, es mirar la realidad no direclamente, sino como se refleja en el espejo de mi imaginación o de mis proyecciones sobre el fuluro. Especular es creer y querer que la realidad será tal cual yo la proyecto. Junto con aspeclos positivos, porque proyectar bien es algo necesario, la especulación a veces se convierte en el arte de vivir del trabajo ajeno: proyecto beneficiarme de lo que otros hacen y producen. Desde esta doble perspectiva podemos aplicar la especulación al modelo neoliberal y al engranaje de la economía de mercado, en la forma que se nos presenta en el país. 
Hemos dicho que el neo-liberalismo no es un dogma de fe porque puede ser objelo de una doble especulación. Quienes nos recomiendan y nos imponen desde fuera el neoliberalismo de mercado especulan sobre nuestra realidad interna, que no la conocen mas que en el espejo de algunas variables macroeconómicas, que terminan en deuda exlerna. Esto es lo que ellos ven directamente; nos ven como deudores simplemente: "si deben, deben pagar", y eso se hace en el mercado internacional. Afirman lo que ellos hacen imposible: "no se puede vivir en estado de deuda y tienen que salir de sus deudas". Desde dentro, los defensores y repetidores del nítido modelo de mercado también especulan sobre la naluraleza del mercado. Se refugian en el espejismo de las leyes anónimas cuando en realidad hay fuerzas concretas. Se refugian en principios generales que sólo se cumplen en casos particulares.

Para especular sobre la sociedad fulurible asienlan en el preámbulo del Plan del Desarrollo Económico y Social 1989-1994 los principios filosóficos de una sociedad libre: el hombre es el fin de toda sociedad; la libertad es la base del progreso humano; la igualdad ante la ley es el garante de la paz social; la juslicia garantiza a cada quien lo que le corresponde; el Estado desempeña un papel subsidiario (MIPLAN, 1990, pp. vii-iv). Los principios filosóficos sustentan los correspondientes postulados económicos: la propiedad privada es condición necesaria para la eficiencia de la producción; el mercado libre asegura la mejor asignación de recursos; la competencia garantiza el funcionamiento del mercado; el Estado tiene un papel subsidiario" (pp. 9-10). En anlerior publicación haciamos algunas reflexiones sobre "la democracia en los principios y postulados del modelo"( Ibisale, 1990a, p. 234). Con la mejor buena voluniad hay que decir que este conjunto de principios y postulados se mueven enire la especulación y el espejismo, o como nos decia Luis de Sebastián mitilican el darwinismo social, la supervivencia del más tuerte. Al entrentar estos postulados y principios con el contenido de los acuerdos de paz, en sus componentes de desmilitarización, derechos humanos; comisión ad-hoc, comisión de la verdad; rectificación en la administración de justicia; y por lo que aquí más directamente nos loca, la recomposición económica, el plan de reconstrucción, la distribución de tierras, el Foro de Concertación Económico-Social..., y los modos y resistencias con que se lleva a cabo el proceso dentro y fuera del calendario, poco es lo que queda de realismo en esos principios y poslulados. Si de algo ha servido el breve repaso a los componentes de nuestro multiplicador compuesto, llegamos a la conclusión de que ese conjunto de principios y postulados to únicoque nos dicen es que nunca han sido valores universales, sino muy privados, en el país, y que para que existan hay que remodelar al modelo. 
Hay mucho de especulacion en el argumento ex-contrario que gustan utilizar los leóricos y los políticos nacionales del neoliberalismo de mercado: el contundente fracaso de los "socialismos reales". Lo primero que llama la alención es que utilicen un argumento seudo-marxista: puesto que el conırario tracasó, en virtud de la ley del péndulo, el verdadero modelo es el contrario del contrario. Pero esla argumentación, que ya aburre, falla en su base hislórica, porque es más importante lo que tienen de similares que lo qe dilerencia a estos "contrarios". En la autocrítica de aquellos regimenes, ellos llegan a la conclusión de que los "socialismos reales" no fueron reales socialismos. Sin alargarnos mucho, lo que tipificó a esos países y al bloque fue el ser regimenes de "minorias politicas", que absorbieron el todo poder, el todo saber y el todo hacer. En ese proceso de autocrítica, que arranca de Perestroika (y sobre el cual ya hemos escrito suficientemente y con suficiente bibliografía (Ibisate, 1991a) 1991b), ellos mismos llegan a la conclusión de que el modelo abandonó las aspiraciones democráticas iniciales, sustituidas por las aspiraciones y privilegios de la minoría dirigente, en quien el pueblo deja de creer a medida que ellos dejan de pensar en el pueblo. Por ello en 1989 sonó la hora de la "leoría del rebalse", el rebalse de la paciencia ciudadana contra las minorias dirigentes. Del centralismo desmesurado a la desintegración de la Unión, a los enfrentamientos interrepublicados, a las guerras civiles, a la mayor inseguridad económica. Siendo sinceros, es mucho más lo que aproxima que lo que dislancia el neoliberalismo moderno de los socialismos reales, que algunos autores han calificado como un "Capitalismo del Eslado". Los dogmatismos económicos han sido y son muy peligrosos en ambos extremos de la ley del péndulo, porque frecuentemente los extremos se tocan.

Hablando en primera persona, quiero cerrar esle acápite final con un comentario que el Dr. Julı S. Ramirez, Direclor del Programa de MaesIría de INCAE, hiciera sobre el fenómenos del Este-europeo, y que viniendo de donde viene son las mejores palabras finales. "No deja de ser inquielante nolar que un número considerable de analistas a nivel mundial interpreten el fenómeno del desplome del orden polílico leninislaestalinisla en la URSS y en su área de dominio en Europa solamente como el triunto del mercado. Es indudable que las enormes fallas generadas por la planificación central, como mélodo básico de la asignación de recursos, han tenido enorme peso en ese descalabro. Es preocupante que esa causa sea percibida por muchos intelecluales de Occidente como la más trascendental o la única de importancia, pues podría llevarnos a conclusiones equivocadas, entre ellas al endiosamienlo del mercado, lomándolo como el medio ideal y perfecto para la asignación 
de los recursos en la sociedad. Existen pocas dudas de que el mercado puede ser un excelente medio para la asignación de recursos eficiente y beneficiosa desde el punto de vista de la sociedad como un todo, siempre y cuando se den algunas condiciones, entre las cuales podemos mencionar dos de especial relevancia hoy: que la distribución de ingreso y riqueza existente en la sociedad sea considerada como aceplable, y que no exislan efectos secundarios (externalidades) de importancia que pudiesen ser ignorados por los consumidores o por los produclores al tomar sus decisiones. Es abundante la evidencia acerca de las fallas del mercado para producir las seffales correctas en muchas circunstancias de ocurrencia cotidiana, para poderla ignorar y deificar el mercado... El progreso ha incrementado nuestras capacidades productivas de manera considerable, permiliendo mayores niveles de consumo y disfrute material de la vida; desafortunadamente el progreso no ha incrementado de manera similar nuestra capacidad de aulocontrol, moderación de nuestros hábitos y solidaridad con nuestros semejantes, poniéndonos al borde del abismo de nuestra propia dignidad, si insistimos en construir una lorma de vida inspirada en el más acaramelado materialismo hedonista. El progreso ha incrementado nueslras capacidades para mejorar la vida y la civilización. Pero desalortunadamente, el progreso lambién ha incrementado nueslra capacidad individual y colecliva para destruir la vida y la naluraleza e infligir sutrimientos a olros" (Ramirez, 1990, p. 229).

Eslas palabras y este artículo de un doctor de Harvard resumen ampliamente las ideas que hemos querido transmilir en el presente comenlario.

\section{REFERENCIAS BIBLIOGRAFICAS}

Abrego, Lisandro (1991), "Los programas de ajusle del FMl: contenido, bases leórico-analílicas y resullados". Realidad Económco-social, $\mathrm{N}^{\mathrm{e}}$ 23 (septiembre-octubre).

(1992). "La crisis fiscal y el problema tributario en El Salvador". $E C A, \mathrm{~N}^{2} 522$ (abril).

Banco Central de Reserva (1992). Programa Monetario y Financiero 1992. San Salvador: Mimeo.

DIES-CENITEC (1991). "La erradicación de la pobreza en EI Salvador". Política Económica, № 4.

- (1992), "Migración y remesas". Política Económica, № 11 (Febrero-marzo).

FUSADES (1992), "El exceso de gaslo y desequilibrio externo de la economia. Boletín Económico y Social, N 77 (abril). 
GAES-MIPLAN (1990). Evolución económica y social. San Salvador: MIPLAN.

Ibisale, Francisco Javier (1989), "Economia social de mercado y economía social con mercado". ECA, No 486-7 (abril-mayo).

- (1990a). "El ajusle estructural: una herencia dilicil". Realidad Económico-Social, № 15 (mayo-junio).

- (1990b). "La ley de privatización bancaria: de la privalización a la privatización". Realidad Económico-Social N 16 (Julio-agosto).

-(1991a). "Los socialismos reales hacen su propia autocrítica". $E C A, N^{0}$ 513-14 (julio-agosto).

(1991b). "Del golpe de Estado de agosto-1991 a los programas de ajuste estructural en la URSS". Realidad -Económico-Social (sepliembre-octubre).

-(1992a). "La política de reconslrucción nacional". ECA, Ne 521 (julio-agosto).

- (1992b). "Tecnología para una economía nacional". Realidad Económico-Social, № 27 (mayo-junio).

Instiluto de Investigaciones Económicas (1987). "Necesidades básicas y reactivación de la economía". Boletín de Ciencias Económicas y Sociales, afio 10, $\mathrm{N}^{2} 4$ (julio-agosto).

IIES-UCA (1992). "Las reformas tributarias en El Salvador, 1989-91: el impuesto sobre la renla". Realidad Económico-Social, № 26, (marzoabril).

McGuire, Michael (1990). "Los cambios de la estruclura tribularia de El Salvador: implicaciones para el desarrollo". Realidad Económico-Social, № 18 (noviembre-diciembre).

Ministerio de Planificación (MIPLAN) (1990). Plan de desarrollo económico y social. San Salvador: MIPLAN.

Montoya, Aquiles (1992a). "El seclor agropecuario reformado y la nueva economia popular". Realidad Económico-Social, № 27 (mayo-junio).

- (1992b). "La nueva economía popular". ECA (julio-agosio).

Ramírez, Julio (1990). "La contrarrevolución soviética". Revista INCAE, Vol. 4, N2 1.

Stein, Eduardo y Salvador Arias (1992). Democracia sin pobreza. San José: DEI.

De Sebastián, Luis (1989), "El neoliberalismo: una negación del liberalismo". Realidad Económico-Social, N 11, pp. 419-36.

Sevilla, Manuel (1984), "Visión global sobre la concentración económica en El Salvador". Boletín de Ciencias Económicas y Sociales, año 8 , № 3 (mayo-junio). 